\title{
Impaired surfactant protein B synthesis in infants with congenital diaphragmatic hernia
}

\author{
Paola E. Cogo*, Manuela Simonato\#, Olivier Danhaive ${ }^{\uparrow,+}$, Giovanna Verlato\#, \\ Giovanna Cobellis ${ }^{\S}$, Francesco Savignoni ${ }^{+}$, Donatella Peca $^{+}$, \\ Aldo Baritussio ${ }^{f}$ and Virgilio P. Carnielli ${ }^{\S}$
}

ABSTRACT: Pulmonary hypoplasia and hypertension account for significant morbidity and mortality in neonates with congenital diaphragmatic hernia (CDH). Whether CDH is associated with surfactant dysfunction remains controversial. Therefore, we measured disaturated phosphatidylcholine (DSPC) and surfactant protein (SP)-B concentration in tracheal aspirates and their synthesis rate in infants with $\mathrm{CDH}$ compared to infants without lung disease.

${ }^{2} \mathrm{H}_{2} \mathrm{O}$ as a precursor of DSPC and $1{ }^{13} \mathrm{C}$-leucine as a precursor of SP-B were administered to 13 infants with $\mathrm{CDH}$ and eight controls matched for gestational age. DSPC and SP-B were isolated from tracheal aspirates, and their fractional synthesis rate was derived from ${ }^{2} \mathrm{H}$ and ${ }^{13} \mathrm{C}$ enrichment curves obtained by mass spectrometry. DSPC and SP-B amounts in tracheal aspirates were also measured.

In infants with CDH, SP-B fractional synthesis rate and amount were $62 \pm 27 \%$ and $57 \pm 22 \%$ lower, respectively, than the value found in infants without lung disease $(p<0.01$ and $p<0.05$, respectively). There were no significant group differences in DSPC fractional synthesis rate and amount.

Infants with CDH have a lower rate of synthesis of SP-B and less SP-B in tracheal aspirates. In these infants, partial SP-B deficiency could contribute to the severity of respiratory failure and its correction might represent a therapeutic goal.

KEYWORDS: Isotope labelling, metabolism, pulmonary surfactants

ongenital diaphragmatic hernia $(\mathrm{CDH})$ is a developmental abnormality that affects one in 2,500-5,000 live births, with mortality reaching 30-60\% [1, 2]. Low lung compliance and global lung immaturity are considered important causes of mortality [3]. Surfactant deficiency could also play a role in this disease, but the issue is undecided. Lack of surfactant phospholipids and proteins has been found in animal models of $\mathrm{CDH}$ [4-7]. In humans, conversely, one study found no change in amniotic fluid or lung lavage fluid phospholipids [8], while another found decreased levels of surfactant protein (SP)-A [9]. Recently, an autopsy study comparing human fetuses with $\mathrm{CDH}$ with age-matched fetuses with no pulmonary diseases found no difference in lung disaturated phosphatidylcholine (DSPC) content and SP expression [10], suggesting that $\mathrm{CDH}$ does not impair surfactant storage and that the surfactant yield might be appropriate for lung size. However, DSPC content was measured from the whole lung, while the surfactant component content of the airways was not studied. Moreover, the study gave a still image of the surfactant life cycle and the small number of fetuses in the study did not allow correlation of the degree of pulmonary hypoplasia with surfactant status. At present no data are available on the turnover of SP-B in humans with $\mathrm{CDH}$.

Clarifying this question could help to decide whether infants with $\mathrm{CDH}$ benefit from surfactant supplementation as, when surfactant was administered to a large series of infants with $\mathrm{CDH}$, an increased requirement of extracorporeal membrane oxygenation was found in addition to increased chronic lung disease and increased mortality [11], although the majority of such infants were treated with a surfactant preparation containing a relatively low amount of SP-B. This notwithstanding, exogenous surfactant is frequently administered to $\mathrm{CDH}$ infants in several nurseries [12].
AFFILIATIONS

*Dept of Medical Cardiac and Cardiac Surgical Paediatrics, Bambino Gesù Children's Hospital, ${ }^{+}$Dept of Medical and Surgical Neonatology, Bambino Gesù Children's Hospital, Rome, \#Dept of Paediatrics, Medical Center and University of Padua, ${ }^{f}$ Dept of Medical and Surgical Sciences, University of Padua, Padua Hospital, Padua,

${ }^{\S}$ Neonatal Division and Paediatric Surgery Division, Institute of Maternal-Infantile Sciences, Polytechnic University of Marche and University of Ancona, Ancona, Italy, and

"Dept of Paediatrics, University of California San Francisco, San Francisco, CA, USA.

CORRESPONDENCE

P.E. Cogo

Terapia Intensiva Cardiochirurgica Ospedale Paediatrico Bambino Gesù Via Giustiniani 3 Rome Italy E-mail paola.cogo@opbg.net

Received: Feb 232012 Accepted after revision: June 032012 First published online: June 142012 
The aim of the present study was to assess surfactant DSPC and SP-B concentrations in the airway fluid recovered from tracheal aspirates in newborns with severe $\mathrm{CDH}$ versus matched controls and to measure the synthesis rate of these critical surfactant components using a dual stable isotope approach.

\section{MATERIAL AND METHODS Patient population}

$13 \mathrm{CDH}$ newborns and eight weight- and gestational agematched controls were studied from 2006 to 2009 with institutional ethical committee approval.

All CDH infants had respiratory failure requiring endotracheal intubation: five were admitted to Bambino Gesù Hospital neonatal intensive care unit (NICU) (Rome, Italy), five to the University of Padova NICU (Padova, Italy) and three to the Polytechnic University of Marche NICU (Ancona, Italy). Nine newborns were enrolled as controls at the neonatal or paediatric intensive care unit of the University of Padova.

Controls were full-term newborns with: 1) no history of lung disease; 2) normal chest radiograph; and 3) inspiratory oxygen fraction $\left(\mathrm{FI}_{\mathrm{I}} \mathrm{O}_{2}\right)<30 \%$ before and at any time during the study period. They were on mechanical ventilation for abdominal or airways malformations or neurological impairment. Inclusion criteria for both groups were: 1) presence of arterial (right radial in $\mathrm{CDH}$ ) and venous lines for clinical monitoring; 2) no evidence of infection; 3) no exogenous surfactant administered; and 4) written informed parental consent. Exclusion criteria were presence of liver failure, defined as transaminases (aspartate aminotransferase and alanine aminotransferase) more than three times normal values, and renal failure (creatinine more than twice normal value).

\section{Protocol}

All CDH infants were treated according to guidelines shared among the three centres. All infants were sedated and ventilated by high-frequency oscillatory ventilation (HFOV) from birth and subsequently weaned to conventional ventilation if mean airway pressure was $<10 \mathrm{cmH}_{2} \mathrm{O}$ and $\mathrm{FI}_{1} \mathrm{O}_{2}<40 \%$. Surgery was postponed until haemodynamic stability was achieved. Controls were on conventional ventilation. Ventilator parameters and gas exchange were recorded every $6 \mathrm{~h}$ and arterial oxygen tension $/ \mathrm{FI}_{1} \mathrm{O}_{2}$ ratio, oxygenation index and alveolararterial $\mathrm{O}_{2}$ delivery were calculated according to standard formulae.

\section{Methods and study design}

All patients received a constant intravenous infusion of $2 \mathrm{mg} \cdot \mathrm{kg}^{-1} \cdot \mathrm{h}^{-1} 1-{ }^{13} \mathrm{C}$-leucine (Cambridge Isotope Laboratories, Andover, MA, USA) dissolved in saline for $24 \mathrm{~h} .{ }^{2} \mathrm{H}_{2} \mathrm{O}$ (Cambridge Isotope Laboratories) was administered as $1 \mathrm{~mL} \cdot \mathrm{kg}^{-1}$ bolus at study onset, then every $12 \mathrm{~h}$ for a $48 \mathrm{~h}$ duration, as intermittent boluses corresponding to $0.0625 \%$ of total fluid intake, in order to maintain a steady state of deuterium enrichment in body water [13].

Blood $(0.6 \mathrm{~mL})$, urine $(1 \mathrm{~mL})$ and tracheal aspirates [14] were collected before the start of the isotope infusion, every $6 \mathrm{~h}$ until $72 \mathrm{~h}$ and then every $12 \mathrm{~h}$ until extubation. Tracheal aspirates and blood samples were centrifuged at $400 \times g$ and $1,300 \times g$, respectively, and supernatants were stored at $-80^{\circ} \mathrm{C}$.

\section{Analysis of tracheal aspirates}

Phospholipids phosphorous was measured in tracheal aspirate samples for $48 \mathrm{~h}$ [15] from the start of the study. DSPC was extracted and separated from tracheal aspirates as reported previously [16], and DSPC fatty acids were derivatised as methyl-esters and measured by gas chromatography [14].

SP-B was measured by ELISA of unfractionated tracheal aspirates obtained at the beginning of the study or within $24 \mathrm{~h}$ [17] using a rabbit antiserum directed against mature SP-B [18].

DSPC and SP-B concentrations were expressed as percentage of total phospholipids and as concentrations in epithelial lining fluid [19].

\section{Isolation of SP-B from tracheal aspirates}

SP-B was isolated from tracheal aspirates and hydrolysed as previously described [20]. Individual amino acids were derivatised into their $N$-acetyl-n-propyl derivatives [21] and the ${ }^{13} \mathrm{C}$ enrichment of leucine was measured by mass spectrometry (GC-MS; Agilent, Milan, Italy).

Plasma amino acids were derivatised according to HUSEK [22] and leucine enrichment was measured by gas chromatography mass spectrometry. Results were expressed as mole per cent excess (MPE).

The ${ }^{2} \mathrm{H}$ enrichment of palmitate-DSPC was analysed by gas chromatography-isotope ratio mass spectrometer (IRMS) and expressed in $\Delta \%$ after correction for isotopic contribution of the derivative group [20]. Urine deuterium enrichment was analysed by a high-temperature conversion elemental analyser coupled with an IRMS (TC-EA-IRMS; Thermo Scientific, Bremen, Germany) [20].

\section{Calculations}

Fractional synthesis rate measurement was performed assuming a steady state. The assumption was based on the following considerations: 1) in all patients plasma ${ }^{13} \mathrm{C}$-leucine and urine ${ }^{2} \mathrm{H}_{2} \mathrm{O}$ enrichments reached steady state within $6 \mathrm{~h}$ of the start of the isotope infusion; 2) the slope of the enrichment curve over time did not deviate significantly from zero between time $6 \mathrm{~h}$ and time $24 \mathrm{~h}$ for plasma leucine and between time $6 \mathrm{~h}$ and time $48 \mathrm{~h}$ for urine ${ }^{2} \mathrm{H}_{2} \mathrm{O}$; 3) the concentrations of DSPC and SP-B in tracheal aspirates did not change significantly during the first $48 \mathrm{~h}$ of the study.

Fractional synthesis rate was calculated from the linear portion of the enrichment curve rise over time relative to the plateau enrichment of the respective precursors $[19,20]$.

Variables were expressed as mean \pm SD or median (interquartile range) as appropriate. Statistical analysis was performed by a nonparametric test (Mann-Whitney test) or by unpaired t-test. The kinetic and quantitative data were correlated with respiratory parameters using Pearson's correlation. Significance was defined as $p<0.05$. Data were analysed using the statistical package SPSS 15 (SPSS Inc., Chicago, IL, USA).

\section{RESULTS}

We recruited 22 mechanically ventilated newborn infants, 13 with $\mathrm{CDH}$ and nine with no lung disease (controls). One control infant was subsequently excluded for major congenital heart disease diagnosed after the onset of the study, hence 21 patients 
completed the study. The clinical features of the two groups are reported in table 1 . Demographics were similar between the two groups, except post-natal age, whereas ventilator parameters were significantly different, as expected by the study design (table 1). In 12 infants, $\mathrm{CDH}$ was diagnosed before 26 weeks gestational age; in one infant the diagnosis was made at birth. Four out of the $13 \mathrm{CDH}$ cases were right-sided and nine were left-sided. They were all sedated and ventilated on HFOV at birth but only six were still on HFOV at the start of the study. One infant with $\mathrm{CDH}$ died from lung hypoplasia before hospital discharge but after study completion. None of the survivors were oxygen-dependent at discharge.

All eight controls required intermittent positive pressure ventilation: two for respiratory failure (due to a congenital diaphragmatic paralysis and cystic lymphangioma), three for urinary and abdominal surgery (two bladder malformations and one hepatic hemangioma) and three for neurological failure (two brain malformations, one hydrocephalus). All control infants survived and were discharged from the hospital. Neither $\mathrm{CDH}$ nor control infants showed evidence of infection during the study period.

In all study infants the isotopic enrichments of urine ${ }^{2} \mathrm{H}_{2} \mathrm{O}$ and plasma ${ }^{13} \mathrm{C}$-leucine were on steady state (linear regression slopes of the enrichment values versus time not significantly different from zero) during the isotope administration (data not shown). Median (interquartile range) urine deuterium enrichment was $7,603(7,382-7,962) \Delta \%$ versus $7,712(7,620$ $7,970) \Delta \%$, and ${ }^{13} \mathrm{C}$-leucine enrichment was 9.5 (7.6-10.1) MPE versus 8.1 (5.9-9.3) MPE in CDH and controls, respectively (not significant).

DSPC amounts in tracheal aspirates were also stable during the study period. Isotope incorporation in SP-B was measured in all study infants, whereas in DSPC it was measured in 20 out of the 21

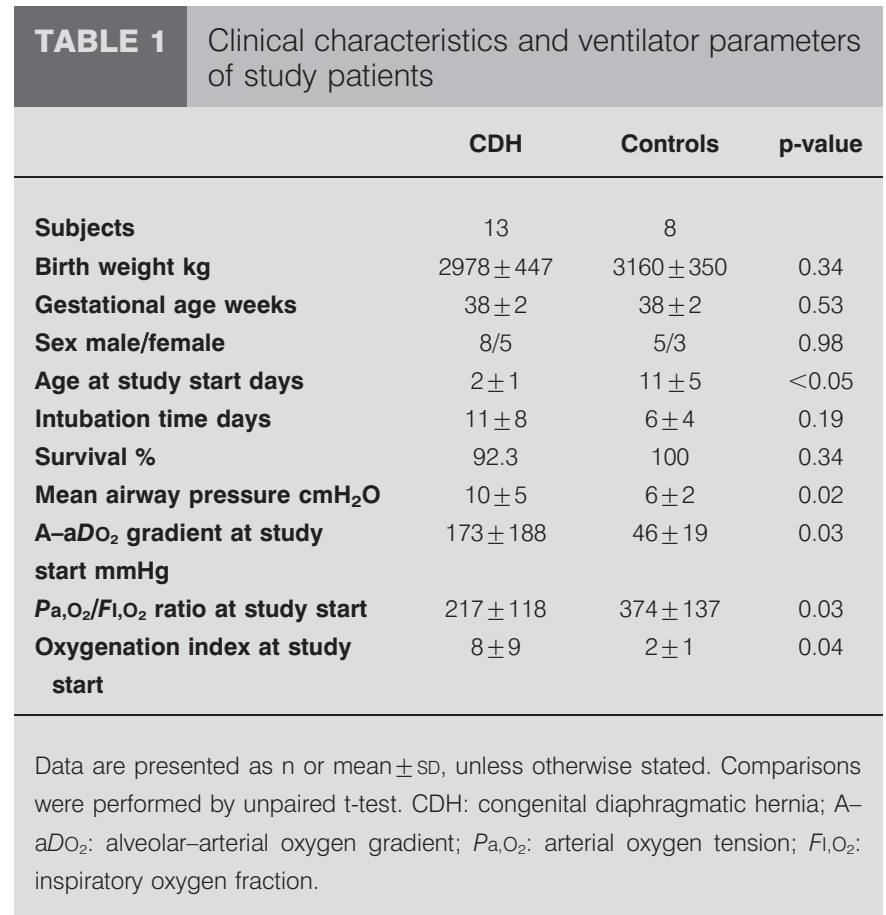

infants (one infant mistakenly received one-tenth of the required ${ }^{2} \mathrm{H}_{2} \mathrm{O}$ dose, hence DSPC enrichments were not detectable).

\section{Surfactant composition}

Basal DSPC and SP-B values in tracheal aspirates, expressed as percentage of total phospholipids, are shown in figure 1. DSPC content was not different between the two groups (median (interquartile range) 43.2 (36.4-50.4) versus 44.6 (30.3-53.9) in $\mathrm{CDH}$ and controls, respectively), while SP-B was significantly lower in $\mathrm{CDH}$ subjects than in controls $(0.19(0.14-0.28)$ versus $0.41(0.18-0.49), \mathrm{p}<0.05)$

\section{Surfactant DSPC and SP-B kinetics}

Pooled enrichment curves of palmitate-DSPC and leucine-SP-B from $\mathrm{CDH}$ and control subjects are shown in figure 2.

As previously reported [22], SP-B turned over at a much faster rate than DSPC both in CDH infants and in controls (2.9-12.4 times faster in $\mathrm{CDH}$ and 14.2-16.2 times faster in controls). SP-B fractional synthesis rates (FSRs) was 33.4 (24.4-43.5)\% per day in $\mathrm{CDH}$ versus 52.0 (33.0-87.9)\% per day in controls $(p=0.03)$, while DSPC FSRs were $5.0(3.5-8.7) \%$ per day and 6.1
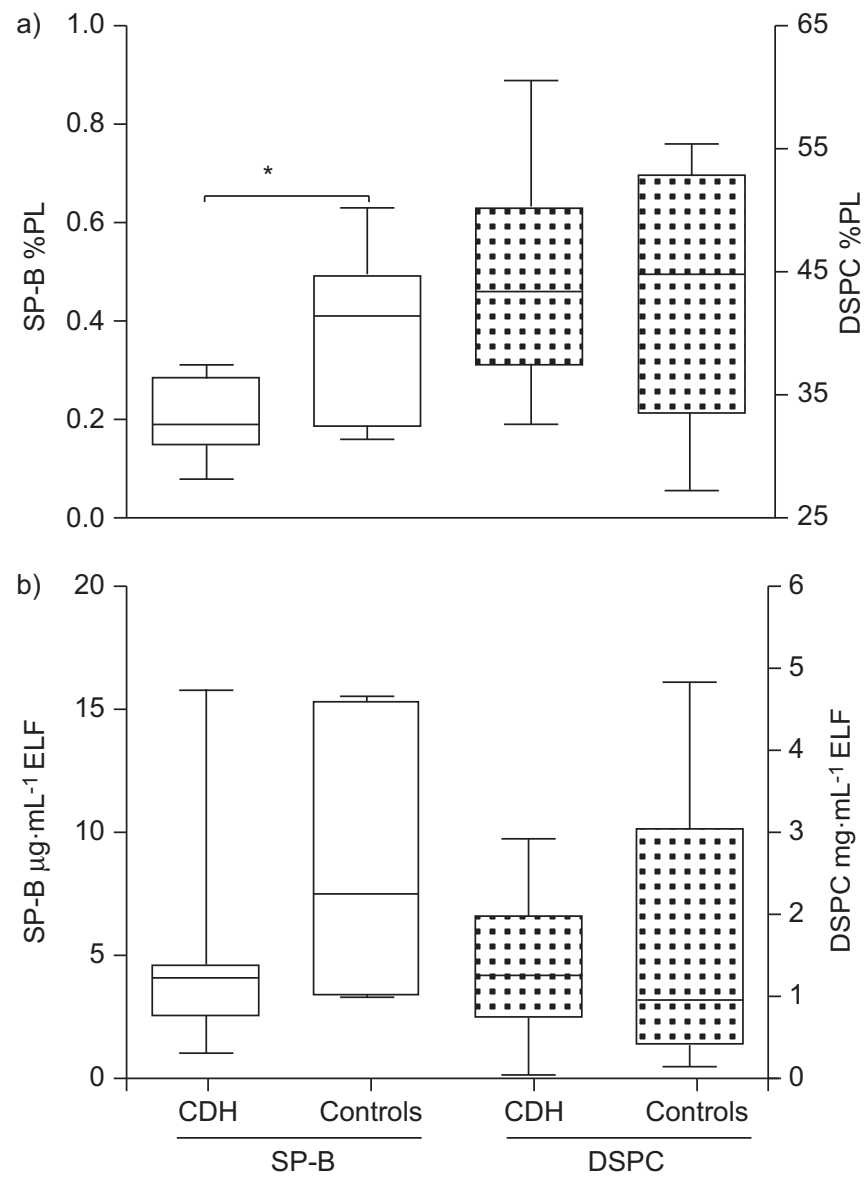

FIGURE 1. Surfactant protein (SP)-B and disaturated phosphatidylcholine (DSPC) in tracheal aspirates from infants with congenital diaphragmatic hernia (CDH) and control infants. SP-B and DSPC values (median and interquartile range) are reported as a) proportion of total phospholipids (PL) and b) epithelial lining fluid (ELF). *: $\mathrm{p}<0.05$ by Mann-Whitney test. 

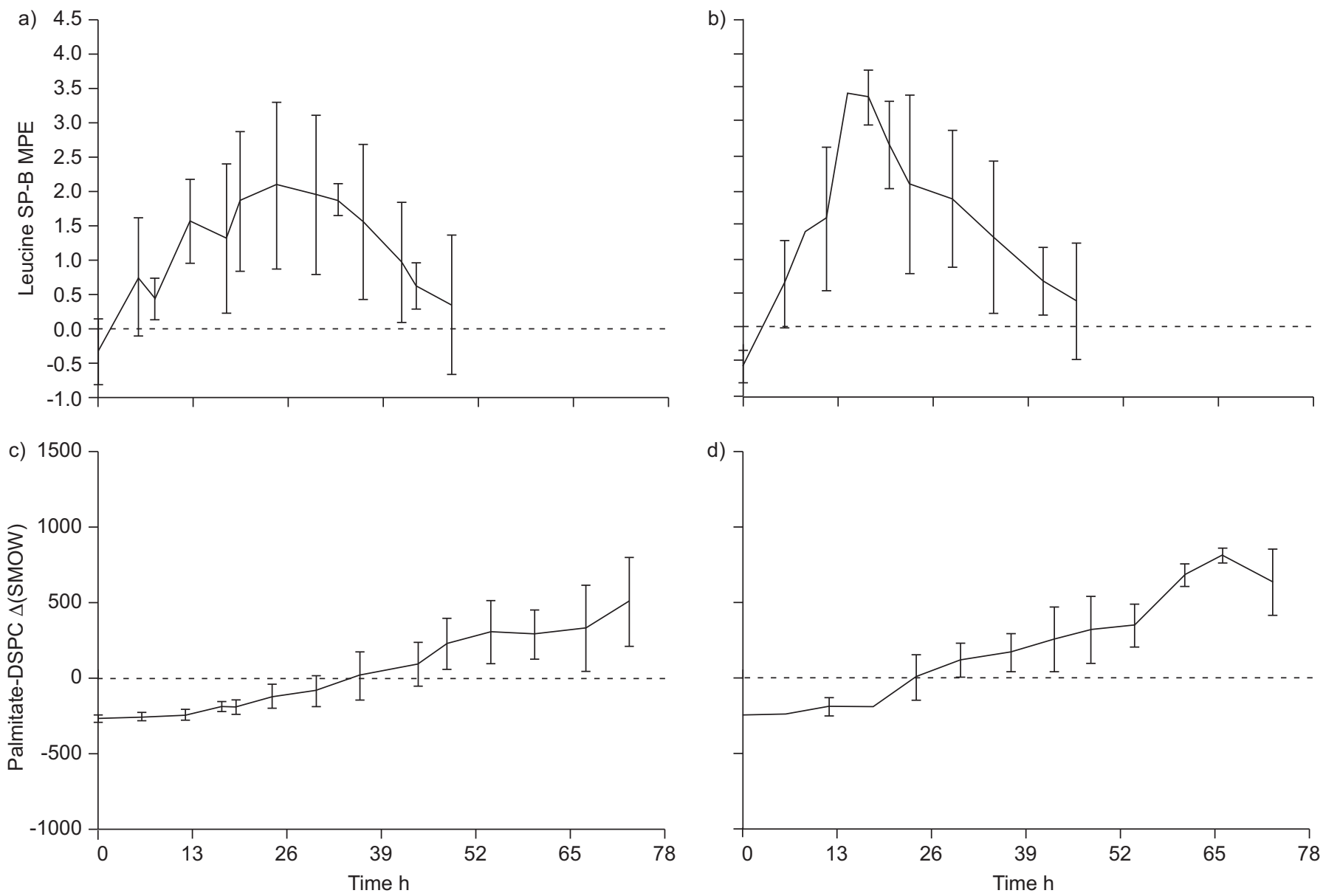

FIGURE 2. Leucine-surfactant protein (SP)-B enrichment curves in a) congenital diaphragmatic hernia (CDH) and b) control infants, and palmitate-disaturated phosphatidylcholine (DSPC) in c) $\mathrm{CDH}$ infants and d) control infants. Data are presented as mean \pm SD. MPE: mole per cent excess; $\Delta(\mathrm{SMOW}){ }^{2} \mathrm{H} /{ }^{1} \mathrm{H}$ versus standard mean ocean water (SMOW).

$(5.2-8.5) \%$ per day, in $\mathrm{CDH}$ and controls, respectively, $(\mathrm{p}=0.31)$ (table 2).

There was a significant direct correlation between SP-B FSR and SP-B percentages of total phospholids $(r=0.544, \mathrm{p}=0.029)$.

In the CDH group, DSPC FSR directly correlated with oxygenation index $(\mathrm{r}=0.632, \mathrm{p}=0.021)$, alveolar-arterial $\mathrm{O}_{2}$ gradient $(\mathrm{r}=0.632, \mathrm{p}=0.021)$ at the start of the study, and

\begin{tabular}{lccc} 
TABLE 2 & $\begin{array}{l}\text { Surfactant protein (SP)-B and disaturated } \\
\text { phosphatidylcholine (DSPC) kinetic parameters } \\
\text { in study infants with congenital diaphragmatic } \\
\text { hernia (CDH) and age-matched control infants }\end{array}$ \\
& CDH & Controls & p-value \\
\hline & 13 & 8 & \\
Subjects n & $33.4(24.4-43.5)$ & $52.0(33.0-87.9)$ & 0.03 \\
SP-B FSR \% per day & $5.0(3.5-8.7)$ & $6.1(5.2-8.5)$ & 0.31 \\
DSPC FSR \% per day & & &
\end{tabular}

Data are presented as median (interquartile range), unless otherwise stated. Comparisons were made by Mann-Whitney test. FSR: fractional synthesis rate. oxygenation index expressed as a mean value during the study $(\mathrm{r}=0.597, \mathrm{p}=0.031)$.

\section{DISCUSSION}

Data regarding surfactant components in $\mathrm{CDH}$ are limited and controversial. Previous studies on sheep fetuses with surgically created diaphragmatic hernias and rat fetuses with nitrofeninduced $\mathrm{CDH}$ reported decreased phospholipids and SP levels in lung tissue, decreased surfactant protein transcripts, and changes in lung compliance [6, 7, 23-25]. However, other authors working on similar $\mathrm{CDH}$ models did not report changes in alveolar surfactant composition [26] or even increased SP expression [27].

Data from clinical studies suggest that phospholipid production is normal, since in human CDH fetuses examined between 33 and 38 weeks, amniotic fluid lecithin to sphingomyelin ratios and phosphatidylglycerol levels were not different from those of historical control data [28]. Our group showed that phosphatidylcholine synthesis is not altered in CDH infants [9, 29]. Finally, an autopsy study found normal total lung DSPC and SP content in CDH compared to normal fetuses, suggesting that surfactant phospholipid endowment in the lungs of CDH infants may be normal [10]; however, this study did not measure airway levels of surfactant components. 
Since surfactant content in the whole lung may not reflect its distribution to the airspaces, we reappraised the subject by comparing mature SP-B and DSPC tracheal aspirate concentrations and synthesis rate in newborns with $\mathrm{CDH}$ compared to newborns with normal lung function. We found that SP-B airway recovery and synthesis rates were significantly decreased in CDH infants, while DSPC recovery and synthesis did not differ from controls, at variance from a previous study where DSPC amount from tracheal aspirates was significantly decreased in CDH infants compared with matched controls [9]. Recovery from tracheal aspirates can be affected by sampling dilution techniques, and thus could be less consistent than kinetic studies that are not affected by dilution.

Accordingly, DSPC FSR directly correlated with the degree of respiratory failure, suggesting an efficient compensatory feedback mechanism, while SP-B FSR did not increase with the severity of respiratory failure. Thus, infants with $\mathrm{CDH}$ appear to have relative SP-B deficiency, presumably due to decreased synthesis, although changes in degradation, in the context of immaturity and ventilation-induced lung inflammation, cannot be excluded based on our data [30-32].

Of note, our data refer to mature SP-B, unlike other studies that do not discriminate between mature SP-B and precursor forms of uncertain origin and significance [33]. We speculate that partial SP-B deficiency, together with lung immaturity and inflammation, significantly contributes to respiratory insufficiency in infants with CDH.

The fractional synthesis rate of SP-B in our $\mathrm{CDH}$ infants ranged from $5 \%$ to $50 \%$, suggesting a spectrum of gravity in this deficiency. The low number of study infants did not allow us to demonstrate a correlation of SP-B FSR with any clinical outcome parameters. Interestingly, looking at all study infants, we demonstrated a direct correlation between SP-B FSR and $\mathrm{SP}-\mathrm{B}$ content in tracheal aspirates $(\mathrm{r}=0.544, \mathrm{p}=0.029)$. It will be interesting to establish in a larger cohort of $\mathrm{CDH}$ infants whether a correlation exists between the degree of respiratory insufficiency and the amount of SP-B in the airways. If this relationship were to be confirmed, SP-B measurement in tracheal aspirates could assist clinicians in deciding whether to administer exogenous surfactant to infants with $\mathrm{CDH}$. This is not a trivial issue, as surfactant treatment can transiently alter gas exchange and lung compliance, with a major risk for complications such as pneumothorax and/or pneumomediastinum in these hypoplastic lungs.

Our study has two major limitations. First, $\mathrm{CDH}$ and controls were not well matched for age at the time of the study and therefore the differences in SP-B concentrations and kinetics could have been attributable to age difference. Unfortunately, there is little information on tracheal aspirate SP-B profile in the early post-natal period. One study found that in pre-term infants beyond the first week of life tracheal aspirate SP-B levels were comparable to those reported in term infants [34] and these levels remained constant during the next 9 weeks after birth. We speculate that, if the differences observed were age-related, they should have affected both DSPC and SP-B.

Secondly, all CDH infants were placed on HFOV at birth, but only six of them were still ventilated on HFOV at the time of the study, while the other seven infants were on conventional ventilation, as were the controls. However, among $\mathrm{CDH}$ infants we found no difference in SP-B FSR between those on HFOV and those on synchronised intermittent mandatory ventilation (data not shown). Experiments in sheep showed that SP-B kinetics are not modified by HFOV [35]. Hence, it is unlikely that differences in ventilation mode were the only cause of our observations.

In conclusion, we analysed DSPC and SP-B airway recovery and synthesis rate in infants with $\mathrm{CDH}$ compared to controls without lung disease. We found that SP-B airway recovery and synthesis rates were significantly decreased in $\mathrm{CDH}$ infants compared to controls, while DSPC recovery and synthesis did not differ. Partial alveolar SP-B deficiency could be a major contributor to respiratory insufficiency in $\mathrm{CDH}$, and its correction might represent a therapeutic goal if new-generation synthetic surfactant containing recombinant SP-B were available.

\section{STATEMENT OF INTEREST}

None declared.

\section{ACKNOWLEDGEMENTS}

The authors thank all intensive care nurses from Bambino Gesù Children's Hospital, Padua Hospital and Salesi Hospital who contributed to the sample collection.

\section{REFERENCES}

1 Chapin CJ, Ertsey R, Yoshizawa J, et al. Congenital diaphragmatic hernia, tracheal occlusion, thyroid transcription factor-1, and fetal pulmonary epithelial maturation. Am J Physiol Lung Cell Mol Physiol 2005; 289: L44-L52.

2 Grethel EJ, Farrell J, Ball R, et al. Congenital diaphragmatic hernia associated with spinal anomalies. Obstet Gynecol 2007; 109: 485-488.

3 George DK, Cooney TP, Chiu BK, et al. Hypoplasia and immaturity of the terminal lung unit (acinus) in congenital diaphragmatic hernia. Am Rev Respir Dis 1987; 136: 947-950.

4 Glick PL, Stannard VA, Leach CL, et al. Pathophysiology of congenital diaphragmatic hernia II: the fetal lamb CDH model is surfactant deficient. J Pediatr Surg 1992; 27: 382-387.

5 Benachi A, Chailley-Heu B, Barlier-Mur AM, et al. Expression of surfactant proteins and thyroid transcription factor 1 in an ovine model of congenital diaphragmatic hernia. J Pediatr Surg 2002; 37: 1393-1398.

6 Suen HC, Catlin EA, Ryan DP, et al. Biochemical immaturity of lungs in congenital diaphragmatic hernia. J Pediatr Surg 1993; 28: 471-475.

7 Thebaud B, Barlier-Mur AM, Chailley-Heu B, et al. Restoring effects of vitamin A on surfactant synthesis in nitrofen-induced congenital diaphragmatic hernia in rats. Am J Respir Crit Care Med 2001; 164: 1083-1089.

8 Moya FR, Thomas VL, Romaguera J, et al. Fetal lung maturation in congenital diaphragmatic hernia. Am J Obstet Gynecol 1995; 173: 1401-1405.

9 Cogo PE, Zimmermann LJ, Rosso F, et al. Surfactant synthesis and kinetics in infants with congenital diaphragmatic hernia. Am J Respir Crit Care Med 2002; 166: 154-158.

10 Boucherat O, Benachi A, Chailley-Heu B, et al. Surfactant maturation is not delayed in human fetuses with diaphragmatic hernia. PLoS Med 2007; 4: e237.

11 Lally KP, Lally PA, Langham MR, et al. Surfactant does not improve survival rate in preterm infants with congenital diaphragmatic hernia. J Pediatr Surg 2004; 39: 829-833. 
12 de Buys Roessingh AS, Dinh-Xuan AT. Congenital diaphragmatic hernia: current status and review of the literature. Eur J Pediatr 2009; 168: 393-406.

13 Cogo PE, Gucciardi A, Traldi U, et al. Measurement of pulmonary surfactant disaturated-phosphatidylcholine synthesis in human infants using deuterium incorporation from body water. J Mass Spectrom 2005; 40: 876-881.

14 Cogo PE, Carnielli VP, Bunt JE, et al. Endogenous surfactant metabolism in critically ill infants measured with stable isotope labeled fatty acids. Pediatr Res 1999; 45: 242-246.

15 Bartlett GR. Phosphorus assay in column chromatography. J Biol Chem 1959; 234: 466-468.

16 Cogo PE, Giordano G, Badon T, et al. Simultaneous measurement of the rates of appearance of palmitic and linoleic acid in critically ill infants. Pediatr Res 1997; 41: 178-182.

17 Kramer HJ, Schmidt R, Gunther A, et al. ELISA technique for quantification of surfactant protein B (SP-B) in bronchoalveolar lavage fluid. Am J Respir Crit Care Med 1995; 152: 1540-1544.

18 Baritussio A, Alberti A, Quaglino D, et al. SP-A, SP-B, and SP-C in surfactant subtypes around birth: reexamination of alveolar life cycle of surfactant. Am J Physiol 1994; 266: L436-L447.

19 Simonato M, Baritussio A, Ori C, et al. Disaturated-phosphatidylcholine and surfactant protein-B turnover in human acute lung injury and in control patients. Respir Res 2011; 12: 36.

20 Cogo P, Baritussio A, Rosso F, et al. Surfactant-associated protein B kinetics in vivo in newborn infants by stable isotopes. Pediatr Res 2005; 57: 519-522.

21 Corr LT, Berstan R, Evershed RP. Optimisation of derivatisation procedures for the determination of $\triangle 13 \mathrm{C}$ values of amino acids by gas chromatography/combustion/isotope ratio mass spectrometry. Rapid Commun Mass Spectrom 2007; 21: 3759-3771.

22 Husek P. Amino acid derivatization and analysis in five minutes. FEBS Lett 1991; 280: 354-356.

23 Glick PL, Leach CL, Besner GE, et al. Pathophysiology of congenital diaphragmatic hernia. III: exogenous surfactant therapy for the high-risk neonate with CDH. J Pediatr Surg 1992; 27: 866-869.

24 Wilcox DT, Glick PL, Karamanoukian HL, et al. Contributions by individual lungs to the surfactant status in congenital diaphragmatic hernia. Pediatr Res 1997; 41: 686-691.
25 Mysore MR, Margraf LR, Jaramillo MA, et al. Surfactant protein A is decreased in a rat model of congenital diaphragmatic hernia. Am J Respir Crit Care Med 1998; 157: 654-657.

26 Brandsma AE, Tibboel D, Vulto IM, et al. Ultrastructural features of alveolar epithelial cells in the late fetal pulmonary acinus: a comparison between normal and hypoplastic lungs using a rat model of pulmonary hypoplasia and congenital diaphragmatic hernia. Microsc Res Tech 1993; 26: 389-399.

27 Van Tuyl M, Blommaart PE, Keijzer R, et al. Pulmonary surfactant protein A, B, and C mRNA and protein expression in the nitrofeninduced congenital diaphragmatic hernia rat model. Pediatr Res 2003; 54: 641-652.

28 Sullivan KM, Hawgood S, Flake AW, et al. Amniotic fluid phospholipid analysis in the fetus with congenital diaphragmatic hernia. J Pediatr Surg 1994; 29: 1020-1023.

29 Cogo PE, Zimmermann LJ, Verlato G, et al. A dual stable isotope tracer method for the measurement of surfactant disaturatedphosphatidylcholine net synthesis in infants with congenital diaphragmatic hernia. Pediatr Res 2004; 56: 184-190.

30 Xu C, Liu W, Wang Y, et al. Depressed exocytosis and endocytosis of type II alveolar epithelial cells are responsible for the surfactant deficiency in the lung of newborn with congenital diaphragmatic hernia. Med Hypotheses 2009; 72: 160-162.

31 Martinez F, Lewis J, Copland I, et al. Mechanical ventilation effect on surfactant content, function, and lung compliance in the newborn rat. Pediatr Res 2004; 56: 19-25.

32 Ito Y, Veldhuizen RA, Yao LJ, et al. Ventilation strategies affect surfactant aggregate conversion in acute lung injury. Am J Respir Crit Care Med 1997; 155: 493-499.

33 Tomazela DM, Patterson BW, Hanson E, et al. Measurement of human surfactant protein-B turnover in vivo from tracheal aspirates using targeted proteomics. Anal Chem 2010; 82: 2561-2567.

34 Ballard PL, Merrill JD, Godinez RI, et al. Surfactant protein profile of pulmonary surfactant in premature infants. Am J Respir Crit Care Med 2003; 168: 1123-1128.

35 Ikegami M, Wada K, Emerson GA, et al. Effects of ventilation style on surfactant metabolism and treatment response in preterm lambs. Am J Respir Crit Care Med 1998; 157: 638-644. 